\title{
Visual disorders associated with cerebral palsy
}

\author{
PETER BLACK \\ From the Royal Air Force Hospital, Ely, Cambridgeshire
}

SUMMARY School children severely afflicted with cerebral palsy, but unselected in regard to their visual status, have been studied. Of 120 children examined only $24(20 \%)$ had normal eyes or ocular adnexae. Squint was found in $52.5 \%$ of the children and significant refractive errors in $50 \%$. There was also a high incidence of strabismic and anisometropic amblyopia (15\%) and visual field defects (11\%). A number of other ocular abnormalities were found, the majority of which were not amenable to any form of treatment. Early identification of treatable ocular defects and their treatment along conventional lines is emphasised. It is also important to identify untreatable defects that may have a bearing on the child's education. These children need all the help available, and visual function should be at its best. A diagnosis of cerebral palsy has usually been made by the time such a child reaches 18 months of age. In view of the high incidence of ocular defects a full ophthalmological assessment should be part of the routine assessment of the child.

Cerebral palsy consists of a group of conditions of different aetiologies but with distinctive clinical features. The motor abnormalities dominate the clinical picture and form the basis for the definition of cerebral palsy that is most widely quoted in the British literature. This is 'a persistent but not unchanging disorder of movement and posture, appearing in the early years of life, and due to a non-progressive disorder of the brain, the result of interference during its development.' ${ }^{1}$ By general agreement specific degenerative and inherited conditions involving the central nervous system are excluded, although in any population of school children with cerebral palsy such conditions may be represented. It is customary to classify cerebral palsy on the basis of the type of motor abnormality and its topography. ${ }^{2}$ Thus the majority of motor disorders are spastic, athetoid, ataxic, or atonic in that order of frequency, and the topography relates to the description of the limb or limbs involved - for example, monoplegia, diplegia, hemiplegia, tetraplegia, and quadriplegia. A child with spasticity involving both lower limbs would be described as having spastic diplegia. While the motor abnormalities are the most apparent clinically, there are commonly associated varying degrees of mental subnormality, emotional instability, and convulsive disorders. In addition sensory abnormalities, particularly deafness and visual disability, are common,

Correspondence to Mr P. Black, Department of Ophthalmology, Great Yarmouth and Waveney District Hospital, Gorleston, Norfolk. and yet the latter still does not seem to merit the attention that it deserves. These multiple manifestations have led to the terms 'brain damage syndrome' $^{2}$ or 'perinatal encephalopathy' ${ }^{3}$ being used, which perhaps are apter descriptions. However, the diagnosis of cerebral palsy is hallowed by tradition and will be retained here.

An estimate of the incidence in Scotland in 1964 was 750 per 1 million of the population. ${ }^{4}$ It is possible that his number will have increased since then owing to improved perinatal care and greater numbers of affected children in better institutional care. So far as can be ascertained the figures are approximately similar for England and Wales. That cerebral palsy may be associated with an ocular abnormality has been known for over a century. ${ }^{5}$ Within the last 2 decades several authors have drawn attention to this $^{6-10}$ and in particular the high incidence of squint ${ }^{11}$ and refractive error. ${ }^{12}$ Authors have also noted the risk of certain groups of children having their visual disabilities ignored or overlooked. ${ }^{13}$ These include children with multisystem disease, mentally subnormal children, and those with neurological disorders. This study concerns the ophthalmological findings in a group of children afflicted with cerebral palsy.

\section{Patients and methods}

All the children that passed through a school for spastics within one 12-month period were examined. 
Fig. 1 Mental versus chronological age in 120 children with cerebral palsy. The continuous line represents the average mental age of the children and the dotted line represents a population where chronological age matches the mental age. For further details see text.

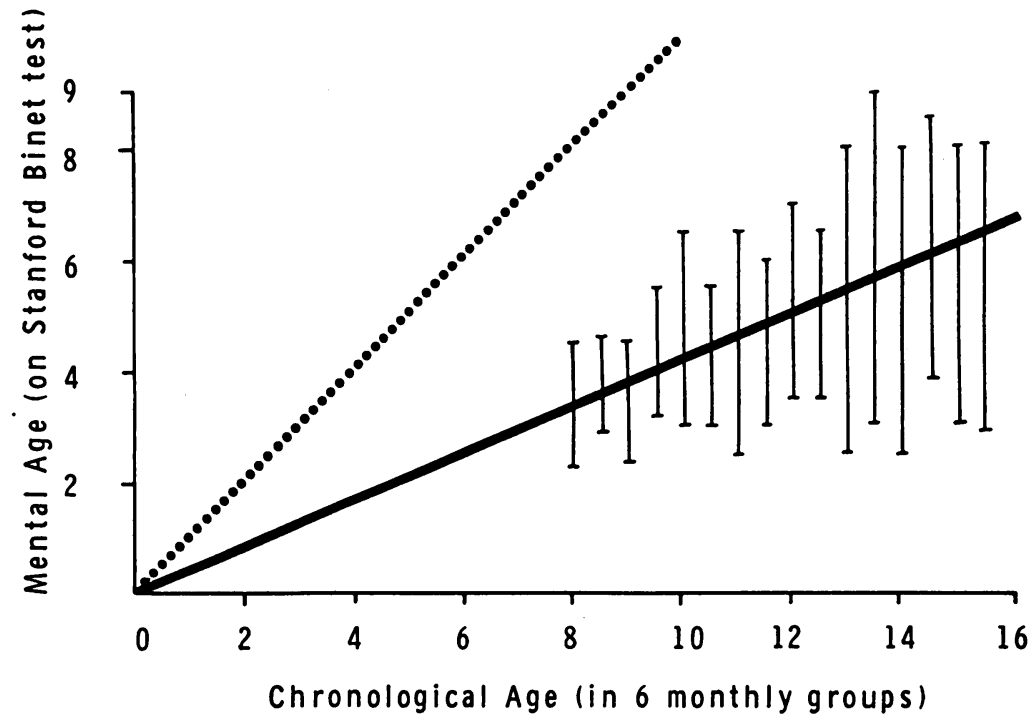

The criteria for selection to the school were that the child had a motor disability consistent with a diagnosis of cerebral palsy and was considered to be educationally severely subnormal, that is with an intelligence quotient (IQ) of between 30 and 50. Sensory handicaps were not considered in selection. There were 120 children between the ages of 6 and 16, of which 53 were female and 67 male. The majority (93\%) were Caucasian.

Fig. 1 shows the mental ages plotted against chronological age in 6-monthly groups. The bars represent the limits of mental age within a particular chronological age group, the continuous line the mean of the mental ages, and the dotted line a population where the mental age is the same as the chronological age. It can be seen that the lowest mental age was just over 2 years and the highest $8 \cdot 5$ years.

All the examinations were performed at the school, in familiar surroundings, with either the child's nurse or teacher present. This is important for 2 reasons. Firstly, these children are easily frightened and require constant reassurance, and, secondly, those children who communicate with sign language need an 'interpreter' with them for the average ophthalmologist to be able to understand their responses. On principle it was decided that no child would be submitted to an examination under general anaesthetic unless the information likely to be gained would directly affect the child's medical care or education. This was not found to be necessary.

The examination consisted of lid position and movements, ocular movements, cover test, visual acuity, visual fields, colour matching, and a cycloplegic refraction and fundus examination some $\mathbf{4 0}$ minutes after the instillation of $1 \%$ cyclopentolate. No adverse reactions to this drug were noted, though an increased incidence of side effects in such children has been reported. ${ }^{14}$

The visual acuity was measured either with Sheridan-Gardiner single optotypes or with the Catford drums. It is appreciated that comparison of acuities obtained by the 2 methods is difficult and that acuity as measured was subject to many variables, not least being the child's mood and ability or will to concentrate. For this reason the results are not reported, although the information gained was of importance for schooling. Visual fields were assessed with the Juler projection scotometer. This instrument was invaluable with children who could not or would not fix on a target. Positive responses were noted by pointing, head turning, or in the case of uncooperative children by visually directed responses. The end wall of a room was used as a screen, this containing approximately the central $40^{\circ}$ of field at the distance used. Colour matching was performed with pieces of felt. The colours used were red, green, dark orange, blue, and dark green arranged in that order on a circular piece of cardboard. The colours used were dictated by commercial availability rather than scientific selection. For educational purposes this was considered adequate. The fundus was examined with the indirect ophthalmoscope.

\section{Results}

Table 1 summarises the types of cerebral palsy seen, classified in the usual manner, and Table 2 lists the light green, light orange, light blue, yellow, dark 


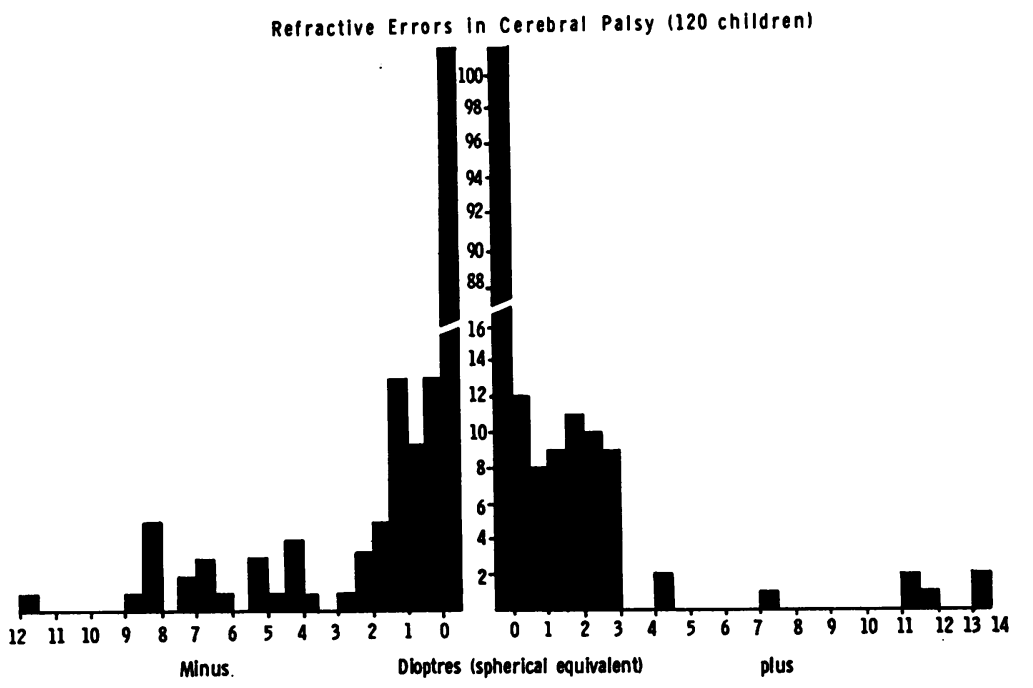

Fig. 2 Histogram showing the range of refractive errors seen in cerebral palsy.

aetiologies where known. In many cases there were a combination of circumstances that could have led to brain damage. In such cases the first event has been taken to be the causative factor. There are several strong correlations. Thus prematurity was associated only with spasticity, either diplegia, tetraplegia, or quadriplegia. Rhesus incompatibility and subsequent kernicterus were associated only with athetosis, though $50 \%$ of athetoids had suffered from a hypoxic episode during or soon after birth. Of the hemiplegics $42 \%$ acquired their lesions as a result of an incident after the perinatal period (road traffic accident, cerebral haemorrhage, meningitis). Infection in utero was presumed to be the cause of the lesions in 11 children, 6 with proved rubella and 2 with cytomegalovirus infection. The other 3 were thought to have suffered from intrauterine rubella, but without supporting laboratory confirmation.

The range of refractive errors found is shown in Fig. 2, plotted in spherical equivalents (sphere $+1 / 2$ cylinder). Age has not been taken into account, since there is evidence to suggest that refractive errors

Table 1 Incidence of type of cerebral palsy in the series, classified by motor abnormality

\begin{tabular}{lcc}
\hline & Number & Percentage \\
\hline Spastic diplegia & 38 & $31 \cdot 6$ \\
Spastic tetraplegia/quadriplegia & 36 & 30 \\
Spastic hemiplegia & 12 & 10 \\
Athetoid & 8 & $6 \cdot 7$ \\
Athetoid with spasticity & 11 & $9 \cdot 2$ \\
Ataxic & 7 & $5 \cdot 8$ \\
Ataxic with spasticity & 3 & $2 \cdot 5$ \\
Others & 5 & $4 \cdot 2$ \\
Totals & 120 & 100 \\
\hline
\end{tabular}

in this group of people do not follow the normal trend of change with age ${ }^{15}$ particularly hypermetropes. It has been postulated that this is related to a failure of maturation of the central nervous system, though skeletal growth is usually normal, albeit modified by the muscle disorders. The use of spherical equivalents permits ease of display but hides a number of significant astigmatic refractive errors. There were 16 such children with astigmatic errors between +1.5 and -1.5 dioptres spherical equivalent. Of the myopes exceeding -4 dioptres 6 had been premature, of which 3 had cicatricial changes of retinopathy of prematurity. There was a small number of aphakic eyes.

The incidence of refractive error found within the major groups of cerebral palsy is shown in Table 3. It can be seen that spastic diplegia in particular carries with it a high risk of refractive error and athetoid cerebral palsy the least risk. Of the children who acquired their cerebral palsy after the perinatal period half had significant refractive errors. The overall incidence of refractive error in this series was exactly

Table 2 Aetiology of cerebral palsy in 120 children

\begin{tabular}{lrc}
\hline & Number & Percentage \\
\hline Asphyxia or birth injury & 37 & $30 \cdot 8$ \\
Prematurity & 24 & 20 \\
Rhesus incompatibility & 5 & $4 \cdot 2$ \\
Presumed placental insufficiency & 9 & $7 \cdot 5$ \\
Infection in utero & 11 & $9 \cdot 2$ \\
Familial & 3 & $2 \cdot 5$ \\
Unknown (with adequate history) & 11 & $9 \cdot 2$ \\
Postnatal insult (mixed aetiologies) & 12 & 10 \\
Inadequate information & 8 & $6 \cdot 6$ \\
Totals & 120 & 100 \\
\end{tabular}


Table 3 Incidence of refractive error greater than -1 to +1.5 dioptres in the major groups of cerebral palsy

\begin{tabular}{lll}
\hline Type & $\begin{array}{l}\text { Number of } \\
\text { patients }\end{array}$ & $\begin{array}{l}\text { Percentage } \\
\text { abnormal }\end{array}$ \\
\hline Spastic diplegia & 38 & 68 \\
Spastic tetraplegia/quadriplegia & 36 & $52 \cdot 8$ \\
Spastic hemiplegia & 12 & $41 \cdot 7$ \\
Athetoid & 8 & $37 \cdot 5$ \\
Athetoid plus spasticity & 11 & $27 \cdot 2$ \\
Ataxic & 7 & $42 \cdot 8$ \\
Ataxic plus spasticity & 3 & 0 \\
\hline
\end{tabular}

$50 \%$, higher than in other series, and is perhaps a reflection of the severity of the cerebral palsy. Twenty-eight pairs of spectacles were prescribed, in addition to those already being worn by 14 children. Patient acceptance was high.

The incidence of squint found in this group of children is given in Table 4. Among the concomitant squints the convergence:divergence ratio was $2 \cdot 3: 1$ syndrome, both associated with spasticity. Among the 16 children with cranial nerve palsies were 5 with 3 rd nerve palsy, 3 with 4 th nerve palsy and 8 with 6 th nerve palsy. The highest incidence was seen in children with spastic hemiplegia.

At this stage it is pertinent to comment on the number of children with amblyopic eyes. In the context of this study amblyopia was presumed to exist when there was a difference of 3 grades on acuity testing between the 2 eyes, or a reluctance to have one eye covered, with correction worn. There had to be a predisposing cause (anisometropia, squint, or ptosis) and an absence of obvious retinal or other lesion. There were 18 children with amblyopic eyes, an incidence of $15 \%$. This could well be an underestimate because of the difficulty of assessing visual acuity in these children.

Table 5 shows the numbers of children with nystagmus, gaze palsy, and ptosis, an incidence of $15 \cdot 8 \%, 4 \cdot 2 \%$, and $2 \cdot 5 \%$ respectively. Nystagmus was found only in the ataxic and spastic types of cerebral

Table 4 Incidence of concomitant and incomitant squint in different types of cerebral palsy

\begin{tabular}{|c|c|c|c|c|c|c|c|}
\hline \multirow[t]{2}{*}{ Type of cerebral palsy } & \multirow[t]{2}{*}{ Number } & \multicolumn{2}{|c|}{ Concomitant squint } & \multicolumn{2}{|c|}{ Paralytic squint } & \multicolumn{2}{|c|}{ Duane's syndrome } \\
\hline & & Number & Percentage & Number & Percentage & Number & Percentage \\
\hline Spastic diplegia & 38 & 18 & $47 \cdot 4$ & 4 & $10 \cdot 5$ & 1 & $2 \cdot 6$ \\
\hline Spastic tetraplegia/quadriplegia & 36 & 12 & $33 \cdot 3$ & 6 & $16 \cdot 7$ & 1 & $2 \cdot 8$ \\
\hline Spastic hemiplegia & 12 & 3 & $25 \cdot 0$ & 3 & 25 & - & - \\
\hline Athetoid & 8 & 2 & $25 \cdot 0$ & - & - & - & - \\
\hline Athetoid with spasticity & 11 & 2 & $18 \cdot 2$ & 2 & $18 \cdot 2$ & - & - \\
\hline Ataxic & 7 & 2 & $28 \cdot 6$ & 1 & $14 \cdot 3$ & - & - \\
\hline Ataxic with spasticity & 3 & 1 & $33 \cdot 3$ & - & - & - & - \\
\hline Others & 5 & 3 & $60 \cdot 0$ & - & - & - & - \\
\hline
\end{tabular}

(usually 8-10:1 in a 'normal' squinting population), and is in line with other workers' findings. Eleven of the concomitant squints had obvious abnormalities of the eye itself (disc abnormalities, retinopathy of prematurity, cataract, anterior chamber cleavage syndrome, and Leber's amaurosis), leaving 32 in which, other than refractive error, no obvious ocular lesions were present. There were 18 children with incomitant squints, of which two had Duane's

Table 5 Nystagmus, gaze palsy, and ptosis in 120 children with cerebral palsy

\begin{tabular}{lllll}
\hline $\begin{array}{l}\text { Type of cerebral } \\
\text { palsy }\end{array}$ & Number & Nystagmus & Gaze palsy & Ptosis \\
\hline $\begin{array}{l}\text { Spastic diplegia } \\
\begin{array}{l}\text { Spastic tetra/ } \\
\text { quadriplegia }\end{array}\end{array}$ & 38 & 7 & 1 & 2 \\
$\begin{array}{l}\text { Spastic hemiplegia } \\
\begin{array}{l}\text { Athetosis with } \\
\text { spasticity }\end{array}\end{array}$ & 12 & 6 & 2 & 0 \\
$\begin{array}{l}\text { Ataxia } \\
\text { Ataxia }\end{array}$ & 7 & 2 & 1 & 0 \\
\hline
\end{tabular}

palsy. Jerky eye movements, not amounting to true nystagmus, were seen in 3 children with spasticity. Eight of the 19 children had searching or pendular nystagmus associated with obvious ocular lesions, with a very marked latent nystagmus superimposed in 4. A further 3 children with pure latent nystagmus were seen, associated in each case with a convergent squint. Of those patients with central nystagmus 3 had upbeat nystagmus and 5 horizontal nystagmus. All of the former and 1 of the latter had pure ataxic

Table 6 Abnormalities of field in 120 children with cerebral palsy

\begin{tabular}{|c|c|c|c|}
\hline \multirow[t]{2}{*}{ Type of cerebral palsy } & \multirow[t]{2}{*}{ Number } & \multicolumn{2}{|l|}{ Field defect } \\
\hline & & $\begin{array}{l}\text { Hemianopia, } \\
\text { number }\end{array}$ & $\begin{array}{l}\text { Constriction, } \\
\text { number }\end{array}$ \\
\hline $\begin{array}{l}\text { Spastic diplegia } \\
\text { Spastic tetraplegia/ }\end{array}$ & 38 & 2 & 3 \\
\hline quadriplegia & 36 & 3 & 4 \\
\hline Spastic hemiplegia & 12 & 1 & - \\
\hline
\end{tabular}


Table 7 Abnormalities of the eye in 120 children with cerebral palsy

\begin{tabular}{|c|c|c|c|c|c|}
\hline \multirow[t]{2}{*}{ Ocular abnormality } & \multicolumn{4}{|l|}{ Type } & \multirow[t]{2}{*}{ Total } \\
\hline & $\begin{array}{l}\text { Spastic } \\
\text { diplegia }\end{array}$ & $\begin{array}{l}\text { Spastic tetral } \\
\text { quadriplegia }\end{array}$ & $\begin{array}{l}\text { Spastic } \\
\text { hemiplegia }\end{array}$ & Other & \\
\hline Microphthalmos & 2 & 2 & - & 1 & 5 \\
\hline Buphthalmos & 1 & - & - & - & 1 \\
\hline Corneal opacity & - & - & 1 & 2 & 3 \\
\hline Cataract & 2 & 1 & - & - & 3 \\
\hline Heterochromia iridis & 1 & 2 & - & - & 3 \\
\hline Uveal coloboma & 1 & 1 & - & 1 & 3 \\
\hline Pigmentary retinopathy & 2 & 1 & - & - & 3 \\
\hline Retrolental fibroplasia & 1 & 1 & 1 & - & 3 \\
\hline Optic atrophy & 2 & 8 & 2 & - & 12 \\
\hline Optic hypoplasia & 2 & 1 & - & - & 3 \\
\hline
\end{tabular}

cerebral palsy. The lesions in these children are presumed to be in the cerebellum. No nystagmus was seen in any child with an athetoid component to his or her disorder. Gaze palsies were seen in 5 patients. Interestingly, 4 had abnormalities of head size, 3 being microcephalic and one hydrocephalic, secondary to neonatal meningitis. Only one gaze palsy was horizontal, the rest being elevator palsies. Ptosis, other than as part of a 3rd nerve palsy, was seen in 3 children, 1 of whom had an associated superior rectus weakness and an amblyopic eye.

Table 6 shows the field defects found in the 120 children examined. They were found only in children with spastic cerebral palsy. It was not found to be particularly difficult to assess field, though there can be no doubt that the method used underestimates the number of individuals affected, particularly with constricted field. There were 13 children (11\%) with gross defects. Only 1 hemianopia was found in the hemiplegia children. Of the children with constricted fields, all but 1 had optic disc or retinal abnormalities. It is noteworthy that field defects were not detected in 8 children with optic atrophy or optic disc hypoplasia. This is a reflection of the difficulty of examining the field in any detail in children whose ability or desire to co-operate may be extremely limited. If one assumes that all these children had defects of field, then a truer incidence overall would be nearer to $17 \%$.

The types of abnormality of the globes found in these children are shown in Table 7. Microphthalmos was seen in association with spasticity in 4 patients and in 1 child with atonic cerebral palsy. In 1 case it was associated with uveal coloboma, central anterior synechiae, shallow anterior chambers, disc hypoplasia, and absence of the septum pellucidum. Rubella was the causative factor in 2 of the children with microphthalmos, as it was in the 1 child with buphthalmos. Two other patients had corneal abnormalities. One had recurrent herpes simplex keratitis, and the other had nonsyphilitic interstitial keratitis associated with neurosensory deafness. Uveal coloboma was seen in 3 cases, an incidence of $2.5 \%$, which compares with other series. ${ }^{9}$ The association of uveal coloboma and mental disorder is well recognised. ${ }^{16} \mathrm{~A}$ surprising finding was 3 cases of heterochromia of the irides. One child had facial hemihypertrophy on the more pigmented side, but there were no other signs of conditions known to be associated with congenital or acquired heterochromia. This abnormality was seen only in spastic children, as was congenital cataract.

So far as the retina was concerned, there were 3 children with cicatricial retinopathy of prematurity. In none had the diagnosis been made before this examination. There were 3 other children with myopia associated with prematurity. None had obvious retinal changes of retinopathy of prematurity, but it was not possible to submit these children to scleral depression to examine the extreme retinal periphery. Rubella retinopathy was seen in 2 children and what was thought on clinical grounds to be Leber's amaurosis in 1 child. Electrical tests of retinal function had not been performed.

Optic atrophy was seen in $10 \%$ of the children. Difficulties may be experienced in deciding clinically whether a disc is pale or atrophic, particularly when co-operation is limited. If doubt existed, the disc was classed as normal, so $10 \%$ may be an underestimate. Disc hypoplasia, seen in 3 children, was diagnosed when there was no doubt the diagnosis and not just for small discs. With 1 exception disc abnormalities were associated only with spasticity. The incidence of colour defects was $8 \%$ of the males, no more than would be expected in the general population.

In this series only 24 children (20\%) had normal eyes on the examination described. Spasticity carried with it the highest chance of ocular abnormality, ranging from $91 \%$ in hemiplegia to $78 \%$ in quadriplegia. Athetoid and ataxic children were least likely to have ocular disorders, this incidence varying 
between $62 \%$ and $72 \%$ depending on whether spasticity was absent or present.

\section{Discussion}

Ocular abnormalities are very common in children with cerebral palsy. In any group of such children there will be a small number with specific syndromes or diseases of which an ocular disorder forms a part, for example, congenital rubella. However, the majority do not have specific and recognisable diseases and fall into a group of brain damaged children. Spastic children are more likely to have ocular defects than athetoid and ataxic children. The pathology in spastic children is more extensive and diffuse, with periventricular haemorrhage, subcortical haemorrhage, and cortical atrophy. In athetoid children it is centred on, although not confined to, the basal ganglia and in ataxic children on the cerebellum. This perhaps explains why spastic children have a higher incidence of ocular defects. The results of visual acuity testing have not been reported for reasons already stated. Douglas ${ }^{9}$ has reported on the range of visual acuities found in such children and commented on the difficulties of assessment. Refractive errors and squint form by far the largest group of abnormalities. Fantl and Perlstein ${ }^{12}$ have shown that myopia predominates in the spastic group. This is explained partly by the high numbers of premature children in this group. If those myopes associated with prematurity are excluded, there is a bias towards hypermetropia in this series, confirming the findings of other workers. ${ }^{17}$ In the dystonic cerebral palsies hypermetropia predominates. This has been explained as a failure of maturation of the visual system related to neonatal hypoxia. ${ }^{15}$ It does seem clear that the normal changes with age that occur in hypermetropia do not occur in cerebral palsied children. However, for this to happen it has been stated that the injury has to occur during the perinatal period, otherwise the incidence of refractive error approaches that of a normal population. In the, admittedly small, number of children in this series who acquired their cerebral palsy at least 21 days after birth, $50 \%$ had refractive errors, and this is contrary to previous findings.

Squint was found in $52.5 \%$ of the children. This compares with previous reported incidences of between $25 \%{ }^{18}$ and $60 \% .^{7}$ There was a relatively low incidence of paralytic squint compared with Smith's series. ${ }^{19}$ In his series the average age of the children was much lower, and this at least in part is a reflection of the tendency for concomitance to develop with age.

The relative infrequency of Duane's syndrome in cerebral palsy has been the subject of comment. ${ }^{9}$ Many authors have considered the treatment of squint unrewarding because of the low rate of success as assessed along conventional lines and the high incidence of consecutive squint following surgery, due in part at least to central obstacles to fusion. However, Hiles and colleagues ${ }^{20}$ treated 234 children with cerebral palsy and squint along conventional lines. They considered that $90 \%$ of their children achieved satisfactory ocular alignment during an average follow-up of just over 4 years. More importantly, they observed 80 children with amblyopic eyes and achieved 'good' results with conventional treatment. There is some evidence that visuospatial dift sulties encountered in such children are exaggerated by the presence of squint. ${ }^{21}$ It thus seems reasonable that every attempt should be made to treat the squint as if the child was otherwise normal: Even the purely cosmetic aspects assume importance, both for parent and patient, though squint surgery may have to be balanced against submitting a child to yet another surgical procedure.

The treatment of amblyopia is also important and the identification at an early age of defects likely to lead to it. The very nature of the child's underlying disability will render him or her accident prone, particularly when the shelter of school is left behind. Although no figures can be found, it must remain a possibility. Every effort should be made where possible to ensure that both eyes have useful vision.

Field defects do not seem to have merited the attention that they deserve. Harcourt ${ }^{22}$ commented on the importance of identifying field defects, and in the children in this series the teachers in particular felt that substantial field defects were a special handicap and that the children did not adapt particularly well to them. Only 1 hemiplegic child was found to have a hemianopia, contrary to at least 1 previous report, which puts the incidence as high as $25 \%$ in cases of infantile hemiplegia ${ }^{23}$ It is important to identify field defects for 3 reasons. Firstly, failure to recognise a field defect, particularly hemianopia, may mislead an examiner performing psychological assessments. The fact that a child does badly when scanning from left to right might be put down to his mental subnormality rather than a right homonymous hemianopia. There may also be reading problems if the child learns to read. Secondly, if that eye is amblyopic, problems could arise when occlusion is planned. Thirdly, teachers aware of field defects may modify the way they physically approach a child, particularly if he or she is hemianopic.

There was 1 spastic child with septo-optic dysplasia. This boy also had an anterior chamber cleavage syndrome, an association not previously described, so far as can be ascertained from the literature.

Defects of the globe are, with the exception of cataract and glaucoma, untreatable. However, their 
recognition may aid in identifying the aetiology of cerebral palsy in that particular case. The rather high incidence of ocular defects found in this series in comparison with other workers' findings, is probably a reflection of the severity of the cerebral palsy. Evidence suggests that the degree of ocular abnormality increases with the degree of mental subnormality.

\section{Conclusion}

Visual disabilities in children with cerebral palsy are common. Errors of refraction, squint, amblyopia, and field defects are seen in a high percentage of these children. When possible it is important to identify and treat these defects along conventional lines. The education of these children relies heavily on visual stimulation, particularly those with sensory deafness. The teachers particularly need to know the visual acuity, defects of visual field, and colour matching ability. Children with multiple handicaps require as much help as possible, and this should include thorough ophthalmological assessment and care. The diagnosis of cerebral palsy has usually been made by the time such a child reaches 12 months of age, and rarely after 18 months. It is at this time that the child should have his or her initial ophthalmological assessment.

\section{References}

1 MacKeith RC, MacKenzie ICK, Polani PE. The Little Club Memorandum on terminology and classification of 'cerebral palsy.' Cerebral Palsy Bull 1959; 1: 23.

2 Minear WL. A classification of cerebral palsy. Pediatrics 1956; 18: 841-52.
3 Allen N, Sherard ES. Developmental and degenerative diseases of the brain. In: Farmer TW, ed. Pediatric Neurology. New York: Harper and Row, 1975: 152-67.

4 Ingram TTS, Jameson S, Errington J, Mitchell RG. Cerebral palsy as a national problem. Clin Developmental Med 1964; 14: $102-5$.

5 Little WJ. Treatment of flat foot or spurious valgus. Lancet $1843-4$; i: $679-84$.

6 Breakey AS. Ocular findings in cerebral palsy. Arch Ophthalmol 1955; 53: 852-6.

7 Guibor GP. Some eye defects seen in cerebral palsy with some statistics. Am J Phys Med 1953; 32: 342-6.

8 Schacat WS, Wallace HM, Palmer M, Slater B. Ophthalmological findings in children with cerebral palsy. Pediatrics 1957; 19: 623-8.

9 Douglas AA. The eyes and vision in infantile cerebral palsy. Trans Ophthalmol Soc UK 1960; 80: 311-25.

10 Graham MV. The spastic child. Proc R Soc Med 1969; 62: 563-4.

11 Smith VH. Strabismus in cerebral palsy. Br Orthopt J 1965; 22: 84-94.

12 Fantl EW, Perlstein MA. Ocular refractive characteristics in cerebral palsy. Am J Dis Child 1961; 102: 36-41.

13 Gardiner P. The 'at risk' concept with reference to visual disorders. Clin Developmental Med 1969; 32: 59-61.

14 Simcoe CW. Cyclopentolate (Cyclogyl) toxicitiy. Arch Ophthalmol 1962; 67: 406-8.

15 Fantl EW, Perlstein MA. Refractive errors in cerebral palsy. Am J Ophthalmol 1967; 63: 857-63.

16 James PLM, Karseras AG, Wybar KC. Systemic associations of uveal coloboma. Br J Ophthalmol 1974; 58: 917-20.

17 Gardiner P. Refractive errors and cerebral palsy. Little Club Clin Developmental Med 1963; 9: 44-7.

18 Asher P, Schonell FE. A survey of 400 cases of cerebral palsy in childhood. Arch Dis Child 1950; 25: 360-79.

19 Smith VH. A survey of strabismus in cerebral palsy. Little Club Clin Developmental Med 1963; 9: 22-36.

20 Hiles DA, Wallar PH, McFarlane F. Current concepts in the management of strabismus in children with cerebral palsy. Ann Ophthalmol 1975; 7: 789-98.

21 Abercrombie MLJ. Eye movements and perceptual development. Clin Developmental Med 1969; 32: 15-24.

22 Harcourt B. Strabismus affecting children with multiple handicaps. Br J Ophthalmol 1974; 58: 272-80.

23 Tizard JPM, Paine RS, Crother B. Disturbances of sensation in children with hemiplegia. JAMA 1954; 155: 628-32. 